\title{
Difficulties in Balint groups: a qualitative study of leaders' experiences
}

\author{
Dorte Kjeldmand and Inger Holmström
}

\begin{abstract}
Background

Balint groups (BGs) are a means of enhancing

competence in the physician-patient relationship and are also regarded as beneficial for GPs' mental health. However, voluntary BGs are still few, some members terminate their participation, and problems are reported in obligatory groups in residency programmes. This raises questions about possible negative aspects of
\end{abstract} BGs.

Aim

To examine difficulties in BGs as experienced by BG leaders.

Design of study

Qualitative study using interviews.

Setting

Eight BG leaders from five countries were interviewed. Method

The interviews focused on the informants' experiences of difficulties in their groups and were analysed with a systematic text-condensation method.

\section{Results}

Three categories of difficulties emerged from the analysis: 1) the individual physician having needs, vulnerabilities, and defences; 2) the group (including the leader) having problems of hidden agendas, rivalries, and frames; and 3 ) the surrounding environment defining the conditions of the group. BGs were found to fit into modern theories of small groups as complex systems. They are submitted to group dynamics that are sometimes malicious, and are exposed to often tough environmental conditions.

\section{Conclusion}

Professionally conducted BGs seem to be a gentle, efficient method to train physicians, but with limitations. Participation of a member demands psychological stability and an open mind. BGs need support from the leadership of healthcare organisations in order to exist.

\section{Keywords}

Balint groups; complex systems theory; education, medical, continuing; family practice; group process; qualitative research.

\section{INTRODUCTION}

Balint group (BG) activity is spread worldwide as one method for physicians' continuous professional development. ${ }^{1}$ The method was developed by Michael Balint for GPs, ${ }^{2}$ and GPs are still the most common target group. In some countries the method is used as a part of medical education or residency programmes in family medicine, ${ }^{3-5}$ and is sometimes mandatory.

The method involves groups of physicians who meet regularly during several years. During these meetings, the physicians' reports of patient encounters are discussed in the presence of one or two leaders trained in the method. Technical and medical details are avoided; focus is on the story of the encounter and the feelings it arouses in the participants, in order to facilitate new ways of understanding the physician-patient relationship.

BGs are considered beneficial for physicians' mental health, and development of competence in the physician-patient relationship. Research has demonstrated a positive effect, ${ }^{6-10}$ and BGs are officially recommended as a means to promote reflection and wellbeing among GPs. ${ }^{11}$ Regardless of this evidence, 50 years after the publication of Balint's book The Doctor, His Patient and the IIIness, ${ }^{2}$ BGs are still few, and it is sometimes difficult to recruit and retain members. Why is this so? The literature on this subject is limited. ${ }^{12-14}$ The number of dropouts was high in the early BGs and Balint introduced 'mutual selection

D Kjeldmand, MD, PhD, GP, Department of Public Health and Caring Sciences, Health Services Research, Uppsala

University and Eksjö Primary Care Centre, Sweden.

I Holmström, RN, PhD, associate professor, Department of Public Health and Caring Sciences, Health Services Research, Uppsala University, Sweden.

Address for correspondence

Dorte Kjeldmand, Health Services Research, Department of Public Health and Caring Sciences, Uppsala University, Eksjö Primary Care Centre, Eksjö, SE-57581, Sweden. E-mail: dorte.kjeldmand@lj.se and kjeldmand@gmail.com

Submitted: 16 January 2010; Editor's response: 9 March 2010; final acceptance: 30 March 2010.

(c)British Journal of General Practice 2010; 60: 808-814.

DOI: 10.3399/bjgp10X532585 
interviews' prior to introduction of new members. The procedure proved successful. ${ }^{10}$ Since then, to the authors' knowledge, no study has been published that addresses BG leaders' experiences of difficulties in their groups.

Balint developed the BG method in the psychoanalytic tradition in which Wilfred Bion also worked. Bion's theories about groups ${ }^{15}$ are taught in training programmes for BG leaders. ${ }^{15}$ Bion defines 'the working group' as characterised by its task; that is, the assignment being the reason for its existence. Other forces occupy the group as well, so-called basic assumptions, and Bion described three types: the dependency group, whose existence depends on one person, often the leader, who is unconditionally admired; the fight-flight group, constantly struggling for its existence, fighting or fleeing, tolerating sacrifices on the way; and the pairing group, anticipating something wonderful being created by two members in the group. These basic assumptions disturb the function of the working group, and the present authors hypothesise that these dysfunctions could explain some difficulties in BGs. However, these theories were not used as an analytical construct during the current study.

The aim of this study was to explore BG leaders' experiences of difficulties in their groups.

\section{METHOD}

Eight BG leaders from Sweden, Israel, UK, Denmark, and the US were chosen strategically to procure a varied sample ${ }^{16}$ in relation to age, nationality, sex, profession, and BG leader experience. They were recommended by members of the national Balint organisations, contacted by e-mail, and asked to participate in an interview study; all those contacted agreed to participate (Table 1). The interviews were conducted face-to-face, and were individual, semistructured, and focused on the following areas:

- the informants' strategies and techniques in the groups;

- experiences of difficulties; and

- reflections on possible risks due to BG participation.

An interview guide ensured that all areas were covered. To obtain rich and personal descriptions, the informants were encouraged to provide concrete examples. The interviews were conducted during 2005 by one author, in Swedish, English, or Danish, lasted from 40 to 70 minutes, and were audiorecorded and transcribed verbatim. An informed consent contract was signed before the interviews. One author analysed the findings, with the other author as coreader, and all the raw material was read through by both authors.

\section{How this fits in}

Professionally conducted Balint groups seem to be a gentle, efficient method to train physicians, but with limitations. Balint groups are found to fit into modern theories of small groups as complex systems, submitted to group dynamics that are sometimes malicious. Participation of a member demands a stable

psychological condition and an open mind, and obligatory Balint groups are questioned. Thus, it should be noted that Balint groups might not suit all GPs, and additional ways to reduce stress and increase competence and job satisfaction should be offered.

The text of the interviews was analysed inductively using a systematic text-condensation method. ${ }^{17}$

1. The texts were read though several times to get a good grasp of the whole. Previous conceptions were actively held back (bracketing).

2. The parts concerning difficulties and dropouts were chosen for further analysis. Here preliminary themes were noted.

3. The text was divided into meaning units (MUs); a new MU was started when there was a shift in meaning.

4. The MUs were grouped according to the themes they belonged to. New categories and themes emerged during this step.

5. The text of the MUs was interpreted, translated, and condensed into the language of the researchers.

6 . The themes were grouped, and main categories and systems emerged.

Analysing the material proved difficult as the informants were found to be verbal professionals, constantly analysing and reflecting. The texts appeared already analysed and interpreted, and it was difficult to find any surplus of meaning. Hence, the narratives of severe difficulties and dropouts from the groups were specifically analysed using an intuitive, empathetically interpretative method, ${ }^{18}$ resulting in themes beyond the informants' own interpretations. In this process, the

Table 1. Description of the eight Balint group leaders interviewed in the study.

General characteristics Female/male

Age, years $\quad 50-77$ (mean 61.4; SD \pm 9.5)

Experience of Balint group leadership Years $2,10,11,15,18,21,23,33$

Number of groups $1,3,3,5,15,16,20,>100$

Professions

GPs

Psychiatrists

Psychologists

Additional education

Psychotherapists

Psychoanalyst

Trainer of Balint group leaders

\section{5}

1 
analysers empathised with the involved group member and used active bracketing of their own preconceptions. As the number of Balint leaders is rather small, it is not possible to mark quotes to make them traceable to the informants for confidentiality reasons.

\section{RESULTS}

Three categories of difficulties were found and related to: the individual member; the group including the leader; and the surroundings of the group. The categories are displayed in Box 1 and presented in the text, illustrated by quotes.

\section{Difficulties related to the individual member}

According to the leaders, some members left the BG because they did not approve of the method, or it did not satisfy their needs; the reasons given would often be the slowness and obscurity of the method because of few explicit rules and instructions:

'Some of those who dropped out, it is only a handful, some of them wanted more about "elephants and how to hunt them", that means practical advice on communication. And that has been part of the criticism against the Balint method, that "we are not told how to do things, and we need that".'

\section{Box 1. Difficulties in Balint groups resulting from the analysis of the interviews.}

Difficulties related to the individual member

- Approval of method

- Needs

- Mental health

- Empathising capability

- Vulnerability

- Family

- Abode

- Sex

- Cultural background

- Specialty

- Workload

- Time

Difficulties related to the group including the leader

- Secrecy

- Frames

- Change of leader

- Dual relations

- Rivalry

- Interventions

- Antipathy

- Hidden agendas

- Scapegoat

Difficulties related to the surroundings of the group

- Economy

- Acceptance

- Healthcare paradigm

- Obligatory
The leaders respected the risks for psychologically vulnerable or mentally ill persons, and none would let physicians with manifest psychotic disorder start in their groups. Some had reluctantly accepted members with known manic-depressive conditions, but with discouraging results:

'I accepted a manic-depressive doctor and when he was manic it was terrible for the group. He was speaking all the time, and when he was depressive he disappeared or he was very sad, but when he was manic it was terrible!'

None of the leaders conducted individual interviews with presumptive new members, although they all mentioned the possibility. The leaders handled problems with empathising capability in different ways, sometimes with understanding and patience; but sometimes these problems were described by the leaders more as a bad quality and an obstacle to the group work:

'I could certainly pick one participant in one of the groups, who later actually gave up general practice. He was not appropriate, he was a very, very rigid thinker and was very harmful in the group [...] He appeared as extremely interested and a great listener, but that was a defence and so when he got challenged he was exceedingly defensive and would not come off: "Now this is the way, when it comes to me now this is the way I do with the patients and this is the right way. I'm sure this is the way we all do in all situations", so he couldn't be wrong.

Interviewer (I): 'And it actually hurt the process in the group?'

'Yes, because people lost respect for him. When he started talking they would look away or whatever. It was difficult because he was one of the older people in that group and it was a mixed group with young trainees as well.'

The leaders appreciated that members could be extra vulnerable temporarily because of private problems, illness, or fatigue. Sometimes a case in the BG unexpectedly brought back old and hurtful memories with shocking effect:

I: 'Have you sometimes felt that you have gone too far when you asked questions?'

'Yes, I have once. I asked a woman who was talking about a case, a man about the same age as her. When she had presented the case and we had talked a lot I asked the question: "Is it possible that this person reminds you of somebody important to you?" She thought for a bit and it proved to be that 
it reminded her of her former husband. I thought that was too intimate, it was not good and she stopped a while later and I concluded that it had been something that disturbed her.'

I: 'She was forced to be personal, private or?'

'No, she got that insight. She said so during that actual group, "I who thought I have worked through it all". So it doesn't really matter in that I think it was quite good that she got that insight, but it might be that she didn't want to get it from the group or from me and she perhaps was afraid that there would come more.'

These episodes were experienced as borderline cases that the leaders considered it their responsibility to avoid. Some leaders would, after challenging episodes in the group, be self-searching and share their self-criticism with the group at the next meeting This was regarded as a way to further enlighten the physician-patient relationship as a parallel process. ${ }^{19}$

The leaders regarded it as their responsibility to know the individual members well and protect them, but they realised that they did not always succeed. Members who were new in the group or had been absent for some time, for example on maternity leave, were considered particularly vulnerable.

The leaders described that common reasons for dropping out of the BG were practical complications concerning private life, family, and abode; such as moving away, maternity leave, or working hours of the spouse.

Sometimes the question of sex was considered significant by the leaders, for instance in single-sex groups, female groups with only one male (a common constellation), or in combination with cultural background. Leaders stated that talking about emotions was not a worldwide phenomenon. Physicians without this experience from thei upbringing could not be expected to join voluntary BGs, which explained why this issue was more common in obligatory groups. However, the compulsory attendance sometimes gave amazing results:

'We had a fellow, I think he was Korean, and just not very - erm - interested or skilled at all in psychosocial issues, because it's not - it's actually something they sort of stay away from. They had never talked about these things in his family; that just wasn't something that he did, so he was very, very concrete about a lot of this. And his growth in this group was - I think - just extraordinary! To move from a place of, not only sort of being able to actively resist it, but literally having no experience with it. It was against the cultural norms of his upbringing.'
The leaders that had experience of group members from different medical specialties found it unrewarding to work with physicians from technical specialties with short patient contacts:

In the first groups I had with those specialist doctors, there was a really high number of dropouts! There was a group of only anaesthetists and their boss had said that participation was obligatory! Ha ha. It ended after one meeting!'

High workload among physicians generally was, according to the leaders, a hindrance to BG participation, as some physicians chose not to spend time on their own personal development, although they knew it was beneficial.

\section{Difficulties related to the group including the leader}

The leaders emphasised the importance that what was said in the group was kept secret from the world outside, even when indiscretions were motivated by good intentions:

'A young woman told the group about something that had been difficult for her, so one of the group members had gone to her work and tried to help her, and she was upset. I thought the same, that it was an abuse of confidentiality.'

The leaders acknowledged their primary obligation of keeping the frames and creating the safe environment in which the members could talk freely. Thus a change of leader destabilised and endangered the group. The relation between the leader and the members was described as sensitive to disturbing factors, such as dual relations; for example, being colleagues outside the group. Rivalry could create conflicts:

'I once had a member in a group who was interested in law, not so much in ethics, and in every case he presented the legal aspect of the case and on the doctor-patient relationship, and on a certain day we really had a dispute in the group and I said: "I don't want that, because it is a kind of escape from more emotional subjective psychological issues". And he said: "no it is very important", and we really had a fight, but that has not often happened.'

I: 'What happened with that participant?'

'He disappeared [...] I think it had to do with that dispute and we both leaders thought it was a struggle between him and me of who was the leader of the group, the formal one and the informal one.' 
The leaders tried to balance the interventions so that the group learned as much as possible and nobody was hurt:

'I don't know whether it played any role if that person later ended or not, I don't know, but there was a woman who presented a case as if she understood it as a very simple case [...] and I understood that she herself hadn't understood the emotional tension that existed in that consultation situation. And I have a feeling that I said it too frankly and she wasn't ready for it, wasn't ready to acknowledge that this was bigger than what she had herself understood.'

The leaders described that sometimes antipathies among members made it impossible to continue; and that unevenness among members created unbalance and, in combination with hidden agendas, the result was sometimes malevolent.

Several scapegoat processes were described, where the group expelled a member, either abruptly or in a longer process with subtle means. According to the Balint method, the leader should prevent this, but it seemed as if the leader sometimes joined the group in the process and later described the member as difficult, uncooperative, and lacking the qualities of a good doctor:

'There was a women who stopped [...] she got a sick leave, for mental problems, and then she was gone, and then she was back for two times, and after that I have not seen her. She is some kind of a dropout - from everything [...] Once in the group they said what they thought, that they were tired of her, and some of them actually said so.' I: 'To her?'

'Yes. She was this kind of person, who, when somebody told something, then she said that she had been there and done it also. If one said that they did research, some of them have a $P h D$, then she could talk about it as if she had done that too, and everybody knew that it was not so.'

\section{Difficulties related to the surroundings}

The leaders experienced that the environment of the $B G$ greatly affected the group. Economy was a strong power, and in the healthcare system translated into patient encounters per hour:

'... they say they need to see patients, 'cause if you count all the faculties not seeing patients and earning money, that's a lot of money, so time all of a sudden is a lot of money these days.'

Attending a BG was often considered inefficiently spent time by management, whose acceptance determined the possibility of physicians joining or staying in the group:

'There are so many other agendas and they have so little time and with the crisis we keep hearing about in government's agenda and so on and so forth, and they are probably right.'

The leaders described how some physicians ended their participation because of a change of employer; and that cultural conceptions in the surrounding society competed with the ideas of the BG, making it unattractive to participate. This would often go hand in hand with a biomedical healthcare paradigm:

I think it has to do with the general philosophy of [...] you know, evidence-based medicine, anything that can be measured, thinking technically and then the enormous competition - "I'm a better doctor than you, how could you make such a mistake" - all the black and white.'

Three leaders had experience of obligatory groups for young physicians. They raised questions about disciplinary problems influencing the process, and about the leaders' obligation towards the vulnerability of the members, who were young and obliged to attend:

'We once had a group with such residents in $X$ and I had a feeling that they didn't want to talk because the director of the school, the professor, told them to talk and they had a feeling, "he can give us commands in every area but he cannot force us to talk about ourselves" [...] That may happen when it is obligatory.'

One leader did not experience problems having obligatory groups. The interns' attendance was not reported and did not influence their approval. On the contrary, the obligation of the BG facilitated the young physicians leaving other work tasks to attend the group.

\section{DISCUSSION}

\section{Summary of main findings}

The findings in this study suggest that participation in Balint groups is not always as uncomplicated as considered previously. Apart from practical and economical issues, indications of occasional malfunction in the group processes were found. These malfunctions could sometimes led to dropouts.

\section{Strengths and limitations of the study}

To study difficulties in BGs is complicated and rarely done. Registration of BGs (especially BGs for specialists) is inadequate, which makes prospective 
studies and follow-ups of effects and failures difficult. Pinder et al interviewed GP trainee-BG members, and observed groups. ${ }^{13}$ In the present study it was decided to ask the leaders of BGs for their experiences. There are methodological problems in doing so. First, there is the general problem of recall bias, because informers' memories will always be inexact. Secondly, as the function of the BG is important to the leaders, and difficulties, especially when leading to dropouts, must be considered failures in some way, it is to be expected that some painful incidents are forgotten or denied. Thus, the narratives in these interviews should be considered a minimal representative of the phenomenon. Most themes appeared saturated except for the issue of obligatory groups, which only three leaders had experience of. One of the authors is a GP with personal experience of both BG membership and leadership. Their preconceptions were brought out in the open and the findings discussed and scrutinised in multiprofessional research seminars. ${ }^{16}$ This process was enhanced by the other author who has no BG experience.

\section{Comparison with existing literature}

Even without follow-up of the expelled BG members mentioned in the interviews, the findings in this study suggest that BGs may not always be beneficial to all members. BG leadership may be conducted in different styles, ${ }^{20}$ but it should aim at creating a safe environment for creative reflection on the physician-patient relationship while protecting the doctor presenting the case..$^{2,7,21}$ However, the present study suggests that modern theories of small groups as complex systems also are applicable to BGs and that they are susceptible to the same dynamics as other groups. According to Arrow et al, groups can be understood as complex systems consisting of dynamics on three levels: local (the individual members' qualities and relations to one another), global (the group's behaviour as group), and contextual (the group in relation to the environment in which it exists). ${ }^{22}$

Change hurts. ${ }^{23,24}$ Sometimes new understanding is unwelcome or too shocking to be internalised. The discussions may bring forth memories or feelings from the members' own lives that are too painful to be compatible with continuation in the group. This risk is higher for psychologically fragile or ill persons, or during periods of turbulence in people's lives. The BG leaders in this study tried to avoid admitting physicians with known mental illness. They all mentioned the possibility of having individual interviews before members started in the group to avoid this, found worthwhile by Balint, ${ }^{10}$ but none used the method.

No clear connections were found between the described difficulties and the theories of basic assumptions about groups by Bion,,$^{15}$ briefly described in the Introduction. Dropouts could be considered a leadership failure, and informers tended to blame the person dropping out. Mostly, leaders described the member as not fitting in, as giving the group a hard time, and that it was a relief when the member was finally expelled. The explanation of what happened was attributed to the person's personality or some quality or unfortunate development within the dropout, or wondering whether this person had the qualities of a physician at all. When members left their BG, it was often explained to be for practical reasons. However, few leaders sought other possible reasons.

Girard describes theories of scapegoating as a fundamental human behaviour. ${ }^{25,26}$ In groups, rivalry or conflicts between members can be organised into a unified aggression towards one member. Rivalry between everybody in a general chaos develops into a stable chaos in the group, where all but one are united against one, the scapegoat, who will be expelled from the group. The expelled member is a personification of the group's aggression, and the group will for some time after this ritual feel relieved and comfortable. The scapegoat may be an ordinary member, but most often the person has some special attributes, sex, race, opinion, or handicap, which in a BG could be problems with empathising capability. One characteristic feature about the scapegoat phenomenon is that it dissolves when recognised.

Some of the BG members that drop out may be physicians whose particular needs for gentle guiding and protection are ignored. Moreover, leaders are participants in groups and susceptible to an intrinsic harmful course of events. The firm frames of the BG method should help in controlling these, but the frames are deranged when there are hidden agendas or states of dependency in the group. The leaders may be aware of Bion's theories on group malfunctions and be able to counteract these, but they may have blind spots for other types of harmful development. The leaders in the present study showed a remarkable disinterest in follow-up and investigating dropouts, which may support this theory. One may theorise further on this track in that the blind spots may co-act with the tradition of integrity of group members, probably grounded on the psychoanalytical origin of the method. Contacts between the leader and the members outside the $B G$ are not regarded as beneficial. This tradition might be questioned in some cases of dropout because it may leave expelled members hurt and prevent the leader from understanding the process and learning from it.

The way a group is started considerably affects the group's development and the way it solves its tasks. Thus Balint work in obligatory groups could be different from voluntary groups. According to Arrow et al, ${ }^{22} \mathrm{a}$ primary issue of members of so-called 'concocted 
groups', predominated and started by external, planned forces, is how to conform to external demands. This contrasts to 'founded groups', initiated and planned by internal forces, as in voluntary BGs, where members coordinate and integrate their own goals, intentions, and expectations. Some leaders in this study reported difficulties with truancy, resistance, and inertia in obligatory groups, reflecting a feeling that the faculty with its disciplinary power was sitting in the room. This unavoidably influences the work in the group because work depends on confidence and openness. On the other hand, if the environment is negative to BGs, making a group obligatory can protect the activity and sanction it as a natural part of the education of young physicians, who otherwise may have difficulties getting away from the demands of the clinical departments.

\section{Implications for future research and clinical practice}

Professionally conducted BGs may seem to be a gentle, efficient method for physicians' training, with positive implications for the patients, yet many physicians choose not to participate. Participation of a member demands a stable psychological condition and an open mind. Physicians without these characteristics would probably benefit more from other methods, for example, mentorship. This makes obligatory BGs an issue for discussion.

The BG leaders in this study were deeply committed to their task. Nevertheless, they reported casualties. These casualties seem to be rather rare but BGs are not as harmless as considered previously. The leaders should be aware of early signs of scapegoating, because this is a harmful and deceptive expression of group malfunction. They should also consider using 'mutual selection interviews' more often.

Many physicians benefit from BGs, some waste their time, and the statement from one leader that 'nobody has become a worse doctor from participating in a BG' may still be challenged. A prospective study is needed of the processes in BGs and the individual member's experiences, both good and bad.

\section{Funding body}

Grants were received from The Health Research Council in the south-east of Sweden (FORSS) and The Academy for Healthcare, Jönköping County Council (FUTURUM), as well as The Swedish Research Council (Vetenskapsrådet) Dnr 5222005-7461 and the Faculty of Medicine, Uppsala University, Sweden.

\section{Ethical approval}

According to the Swedish law (2003:460), approval from ethics committee was neither needed nor applied for. Ethical regulations and guidelines according to the law were followed. The interviewees agreed to participate after being informed of the aims, methods, and anticipated benefits of the study. They were guaranteed confidentiality and informed that they were at liberty to abstain from participating, and were free to withdraw from the study at any time.

\section{Competing interests}

The authors have stated that there are none.

\section{Acknowledgements}

We wish to thank the participating Balint group leaders. We also thank Ann Malmström for mentorship and encouragement, and Henning Pedersen, Marie BäckströmAndersson, and other colleagues at Eksjö Primary Care Centre, for making research possible while being a GP.

\section{Discuss this article}

Contribute and read comments about this article on the Discussion Forum: http://www.rcgp.org.uk/bjgp-discuss

\section{REFERENCES}

1. Salinsky J. The Balint movement worldwide: present state and future outlook: a brief history of Balint around the world. Am J Psychoanal 2002; 62(4):327-335.

2. Balint M. The doctor, his patient and the illness. 2nd edn. London: Pitman Medical Publishing Co Ltd, 1964.

3. Johnson AH. The Balint movement in America. Fam Med 2001; 33(3): 174-177.

4. Johnson AH, Brich CD, Hamadeh G, Stock R. The current status of Balint groups in US family practice residencies: a 10-years follow-up study, 1990-2000. Fam Med 2001; 33(9): 672-677.

5. Torppa MA, Makkonen E, Mårtenson C, Pitkälä KH. A qualitative analysis of student Balint groups in medical education: contexts and triggers of case presentations and discussion themes. Patient Educ Couns 2008; 72(1): 5-11.

6. Kjeldmand D, Holmström I, Rosenqvist U. Balint training makes GPs thrive better in their job. Patient Educ Couns 2004; 55(2): 230-235.

7. Kjeldmand D, Holmström I. Balint groups as a means to increase job satisfaction and prevent burnout among general practitioners. Ann Fam Med 2008; 6(2): 138-145.

8. Turner AL, Malm RL. A preliminary investigation of Balint and non-Balint behavioural medicine training. Fam Med 2004; 36(2): 114-117.

9. Margalit A, Glick S, Benbassat J, et al. Promoting a biopsychosocial orientation in family practice: effect of two teaching programs on the knowledge and attitudes of practicing primary care physicians. Med Tech (Stuttg) 2005; 27: 613-618.

10. Balint M, Balint E, Gosling R, Hildebrand P. A study of doctors. London: Tavistock's Publications Limited, 1966.

11. Swedish Medical Association. Better continuing professional development (Official recommendation published by The Swedish Medical Association). Stockholm: Swedish Medical Association, 2001.

12. Musham C, Brock CD. Family practice residents' perspective on Balint group training: in depth interviews with frequent and infrequent attenders. Fam Med 1994; 26(6): 382-386.

13. Pinder R, McKee A, Sackin P, et al. Talking about my patient: the Balint approach in GP education. Occas Pap R Coll Gen Pract 2006; (87): 1-32.

14. Graham S, Gask L, Swift G, Evans M. Balint-style case discussion groups in psychiatric training: evaluation. Acad Psychiatry 2009; 33(3): 198-203.

15. Rioch MJ. Wilfred Bions teorier om grupper [The work of Wilfred Bion on groups]. In: Jern S, Boalt Boëthius S, Hidman U, Högberg B (eds). Grupprelationer [Group relations]. Stockholm: Natur och Kultur, 2004: $48-63$.

16. Malterud K. Qualitative research: standards, challenges and guidelines. Lancet 2001; 358(9280): 483-488.

17. Malterud K. Kvalitative metoder i medicinsk forskning [Qualitative methods in medical research]. Lund: Studentlitteratur, 1998.

18. Karlsson G. Psychological qualitative research from a phenomenological perspective. Stockholm: Almqvist and Wiksell International, 1995.

19. Playle JF, Mullarkey K. Parallel process in clinical supervision: enhancing learning and providing support. Nurse Educ Today 1998; 18(7): 558-566.

20. Merenstein JH, Chillag K. Balint seminar leaders: What do they do? Fam Med 1999; 31(3): 182-186.

21. Johnson AH, Nease DE, Milberg LC, Addison RB. Essential characteristics of effective Balint group leadership. Fam Med 2004; 36(4): 253-259.

22. Arrow H, McGrath J, Berdahl J. Small groups as complex systems. Thousand Oaks, CA: Sage Publications, Inc., 2000.

23. Holmström I, Rosenqvist U. Interventions to support reflection and learning: a qualitative study. Learn Health Soc Care 2004; 3: 203-212.

24. Kaplan S, Greenfield S, Ware J. Assessing the effects of physician-patient interactions on the outcomes of chronic disease. Med Care 1989; $27(3$ Suppl): $110-127$.

25. Girard R. The scapegoat. Baltimore: The Johns Hopkins University Press, 1986.

26. Jensen HJL. René Girard. Viborg: Forlaget Anis, 1991. 